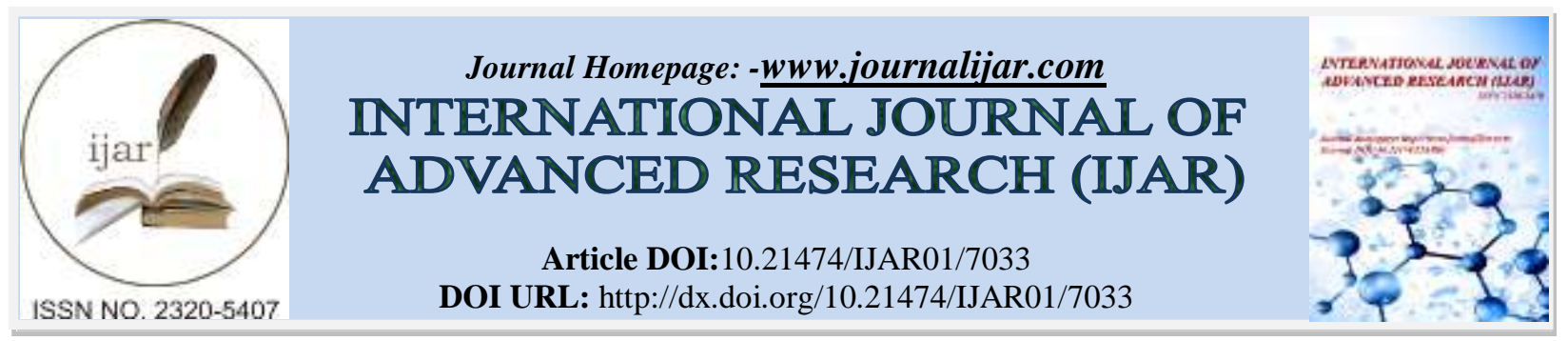

RESEARCH ARTICLE

\title{
EVALUATION OF THE EFFECT OF FEEDING ON PORTULACA OLERACEA SEED OIL ON BIOSYNTHESIS OF LONG CHAIN POLYUNSATURATED FATTY ACIDS IN RATS.
}

\begin{tabular}{|c|c|}
\hline Biochemi & $\begin{array}{l}\text { Medhat Mostafa Abozid. } \\
\text { nent, Faculty of Agriculture, Menoufia University. }\end{array}$ \\
\hline Manuscript Info & Abstract \\
\hline $\begin{array}{l}\text { Manuscript History } \\
\text { Received: } 05 \text { March } 2018 \\
\text { Final Accepted: } 07 \text { April } 2018 \\
\text { Published: May } 2018 \\
\text { Keywords:- } \\
\text { Alpha-linolenic acid; Docosahexaenoic } \\
\text { acid; Eicosapentaenoic acid; Purslane } \\
\text { seed oil. }\end{array}$ & $\begin{array}{l}\text { Feeding on foods with high levels of omega } 3 \text { (n-3) fatty acids is a } \\
\text { major challenge in Egypt because most of the oils used in nutrition are } \\
\text { characterized by high content of n- } 6 \text { fatty acids and low content of n-3 } \\
\text { fatty acids. It is so difficult to obtain n-3 fatty acids from cold-water } \\
\text { fish for their high price and mercury pollution. So you should look for } \\
\text { new alternatives such as purslane (Portulaca oleracea L.) seed oil } \\
\text { which is rich in } \alpha \text {-linolenic acid (ALA), the precursor of the rest of the } \\
\text { omega } 3 \text { fatty acids (n-3) family (C20:5 or eicosapentaenoic acid } \\
\text { [EPA] and C22:6 or docosahexaenoic acid [DHA]). This study is } \\
\text { designed to evaluate the hepatic bioconversion of ALA and linoleic } \\
\text { (LA) to long chain polyunsaturated fatty acids (LCPUFA) and the } \\
\text { statue of liver in male albino rats fed on purslane seed oil. Three } \\
\text { experimental groups (n= } 10 \text { rats each group) were feed on these three } \\
\text { different oils (sunflower oil, olive oil and purslane seed oil) for } 30 \\
\text { days. Purslane seed oil increased ALA, EPA and DHA in liver } \\
\text { compared with sunflower oil and olive oil groups without any changes } \\
\text { in the parameters which express liver damage. It is concluded that } \\
\text { purslane seed oil may be good nutritional source for providing n-3 fatty } \\
\text { acid (ALA, EPA and DHA). }\end{array}$ \\
\hline
\end{tabular}

Copy Right, IJAR, 2018,. All rights reserved.

\section{Introduction:-}

$\alpha$-linolenic acid (C18: 3 n-3, ALA) and linoleic acid (C18: 2 n-6, LA) are considered essential fatty acids for mammals because the body's need for them to form vital compounds (prostaglandins and Leukotrienes) with the body's inability to build them (Holman, 1998; Cunnane, 2003; Nakamura and Nara, 2004). Therefore, humans must take ALA and LA in the diet. Common vegetable oils (corn, sunflower and soybean) contain two essential fatty acids, but the presence of LA is much higher than that of ALA (Kamal-Eldin and Andersson, 1997). Many researches points to the important physiological roles played by EPA and DHA for the human body, whether in the stages of childhood through different stages of growth and also for the elderly (Harris, 2009; Kanai et al., 2011; Li and Hu, 2009; Picq et al., 2010)

In general, humans can obtain the long chain polyunsaturated fatty acids (LCPUFA) from the family of omega 3 (EPA and DHA) and omega 6 (Arachidonic acid [C20:4 n-6 or AA]) in one of two ways: either directly ingested through different foods or bio-converted from two essential fatty acids (ALA for omega 3 and LA for omega 6) (Brenner, 2003). The dependence on consumption of EPA and DHA directly is usually low for different reasons; first is the high price of cold water fish (rich source for EPA and DHA); second is theses fishes polluted with 
mercury; and finally, vegetarians people do not eat fish completely; so making dependence on the conversion of ALA to EPA and DHA increasingly of concern to researchers (Cunnane, 2003).

Since the same group of enzymes (desaturases, chain-elongases and eicosanoid synthesis) which works to synthesis eicosanoid in three fatty acids families (omega 3, omega 6 and omega 9) so ALA (18:3n-3) competes with LA (18:2n-6) and oleic acid (18:1n-9) (Dinh et al., 1993; Lands et al., 1992), for this reason the balance between LA and ALA is one of the most important factors in bio-synthesis and accumulation of EPA and DHA (Araya et al., 2010). Commonly used oils in different diets in Egypt (soybean, sunflower and corn) are characterized by higher content of LA compared to ALA, which leads to n-6/n-3 ratio up to 20:1(Simopoulos, 2008); while the health food recommendations indicate that the best $n-6 / n-3$ ratio is $1: 1$ and the worst estimate should not exceed 1:5 (MolendiCoste, et al., 2011). Because of this we must look for alternative sources of vegetable oils characterized by a high percentage of ALA. New dietary sources of ALA (precursor of EPA and DHA biosynthesis) require new studies to evaluate the relation between increasing ALA and accumulation of EPA and DHA.

Purslane (Portulaca oleracea L.) is a widely distributed weed which besides being used as food was also used in traditional medicine (Liang et al., 2014). Purslane seed oil contain high amount of unsaturated fatty acid with high concentration of ALA (close to $40 \%$ of total fatty acids) (Liu et al., 2014; Osman and Hussein, 2015) which make this oil good source of ALA (to study bioconversion to EPA and DHA). Studies indicate that purslane contains many active substances (vitamins, minerals and polyphenolic compounds) (Ebrahimzadeh et al., 2009; Liu et al., 2000), which led to its important therapeutic properties as hepatoprotective agent (Abdalla and Mohamed, 2010), antioxidant, hypolpidemic and hypoglycemic agent (Abdalla, 2010).

Rat is similar to humans in the biosynthesis pathways of EPA and DHA (Nakamura and Nara, 2004), making them a good example for studying ALA - EPA and DHA bioconversion. The aim of this work was to evaluate the biosynthesis of EPA and DHA in rats fed with diets containing purslane seed oil as sources of ALA.

\section{Materials and methods:- \\ Materials:-}

All animal diets components brought from the local market. The kits for transaminases (aspartate transaminase or AST and alanine transaminase or ALT) were received from Diamond Company, Cairo, Egypt.

\section{Extraction of purslane seed oil:-}

Purslane seed cleaned to remove impurities, and then dried at $50^{\circ} \mathrm{C}$ in an oven. Dried seeds crushed into powder. Oil was extracted by using hexane $\left(60^{\circ} \mathrm{C}\right)$ in Soxhlet apparatus, the process of extraction carried out for $6 \mathrm{~h}$.

\section{Animal and diets:-}

Thirty male Albino rats weighing 110 - 125 g were obtained from Research Institute of Ophthalmology, Giza, Egypt. Rats were divided into three groups (ten per group). The animals in all groups were fed on diets correspond to standard rat feeding requirements (20\% protein, $10 \%$ fat, $65 \%$ carbohydrates and $5 \%$ micronutrients) according to Orellana et al., (2002). Groups were divided into their fat source in each diet as follow: sunflower oil group (SFO) contained 10\% sunflower oil, olive oil group (OO) contained 10\% olive oil and purslane seed oil group (PSO) contained $10 \%$ purslane seed oil. Diets and water were available ad libitum during all experimental period (one month). At the end of the experimental period blood samples were collected from the eye plexuses and serum was separated for the estimation of both ALT and AST enzymes activities.

\section{Liver samples preparations:-}

Liver samples from all tested groups were divided into two parts: first part was kept for further lipid extraction (frozen in liquid nitrogen), while the second part saved in formalin, fixed in paraffin and stained for morphology examination (by using hematoxylin-eosin).

\section{Lipid extraction from liver samples:-}

Liver tissues were prepared for lipid extraction by using chloroform and methanol mixture to extract lipids from tissues (Bligh and Dyer, 1959). 


\section{Liver morphology assessment:-}

In order to determine necrosis in liver cells and evaluate liver deterioration, liver samples has been unloaded from paraffin blocks and stained with hematoxylin-eosin then examined by a pathologist (Bancroft et al., 1996).

\section{Determination of transaminases:-}

Serum AST and ALT enzymes activities were measured using specific kits according to the method described by Young, (1990).

Identification and estimation of fatty acids by gas chromatography (GC):-

Fatty acids analyses (for oils used in diets and lipid extracted from liver tissues) were performed by GC. Samples treated with methanolic boron trifluoride to transform into fatty acid methyl esters (FAME) (Firestone, 1997). The GC of FAME was performed by using Agilent Technologies 7890A GC equipped with flame ionization detector (PE Auto System XL) with auto sampler and Ezchrom integration system and helium was the carrier gas. Oven temperature was $200^{\circ} \mathrm{C}$ injector and detector $250^{\circ} \mathrm{C}$.

\section{Statistical analysis:-}

The results were expressed as the mean \pm SD and they were analyzed statistically using the one-way analysis of variance ANOVA followed by Duncan's test. In all cases $p<0.01$ was used as the criterion of statistical significance.

\section{Results:-}

Fatty acids composition of different oils in experimental diets:-

Table (1) shows the fatty acids compositions of sunflower, olive and purslane seed oils which used in preparation experimental diets. As shown from the table, sunflower oil is characterized by significantly higher content of linoleic acid (LA) (73.24\%), while containing $10.23 \%$ oleic acid and $6.56 \% \alpha$-linolenic acid (ALA). The results also indicated that oleic acid is the largest component in olive oil (70.22\%), while LA represented $14.57 \%$. On the other hand, purslane seed oil showed different results in terms of the presence of unsaturated fatty acids; the value of ALA was the highest (38.75\%) followed by oleic acid (17.85\%) and LA (16.77\%).

Table 1:-Fatty acids compositions of sunflower, olive and purslane seed oils

\begin{tabular}{|l|l|l|l|}
\hline Fatty acids & Sunflower oil & Olive oil & Purslane seed oil \\
\hline Palmitic acid (C16) & 3.33 & 10.3 & 7.55 \\
\hline Stearic acid (C18) & 6.56 & 2.11 & 8.14 \\
\hline Oleic acid (C18:1 n-9) & 10.23 & 70.22 & 17.85 \\
\hline Linoleic acid (LA) (C18:2 n-6) & 73.24 & 14.57 & 16.77 \\
\hline Alpha-linolenic acid (ALA) (C18:3 n-3) & 1.23 & 0.78 & 38.75 \\
\hline Arachidic acid (C20) & ND & ND & 6.32 \\
\hline n-6/n-3 & 59.54 & 18.68 & 0.43 \\
\hline
\end{tabular}

\section{Body weight and food intake:-}

The results obtained in Table (2) indicated that there were no significant differences in both initial and final body weight or in food intake of all tested groups during the one month of treatment. No significant difference in liver weights among all tested groups (Table 2).

Table 2:-Initial and final body weight and liver weights of the different groups

\begin{tabular}{|l|l|l|l|}
\hline Parameter & SFO & OO & PSO \\
\hline Initial body weight & $112.45 \pm 4.5$ & $114.43 \pm 3.65$ & $115.77 \pm 5.61$ \\
\hline Final body weight & $245.21 \pm 6.45$ & $253.34 \pm 5.23$ & $249.66 \pm 4.91$ \\
\hline Liver weight & $14.34 \pm 2.45$ & $13.56 \pm 2.11$ & $12.98 \pm 3.26$ \\
\hline
\end{tabular}

(SFO) sunflower oil group; (OO), olive oil group; (PSO) purslane seed oil group. Values represent the mean \pm SD for 10 rats in each group. There were no significant differences in all groups.

\section{Estimate of liver damage:-}

All groups showed normal AST and ALT activities (Fig. 1). The histological examination of liver cells from the OO and PSO groups under study showed that feeding on olive oil or purslane seed oil didn't lead to any undesirable changes in the form of liver cells under the microscope (Fig. 2). All the oils used in the experiment didn't have any 
negative effect on the liver functions (AST and ALT activities) and didn't cause any damage or deterioration of liver cells.

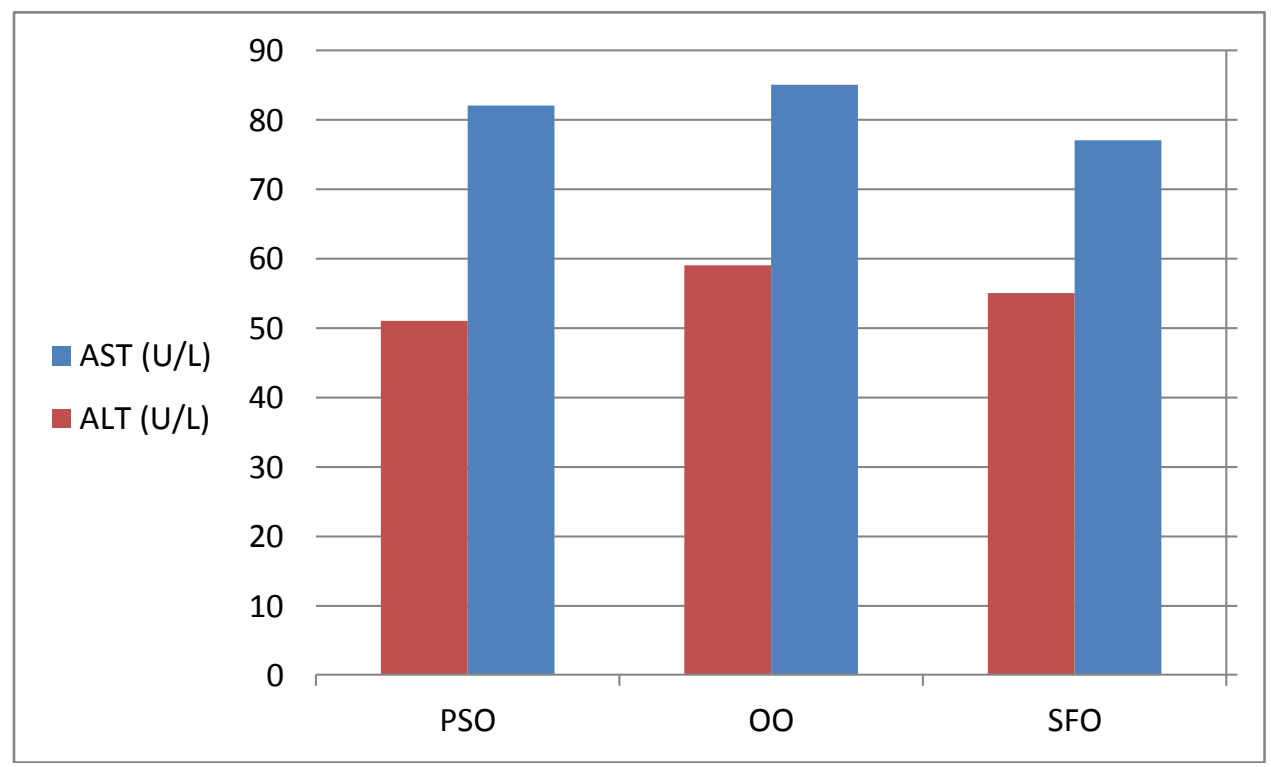

Fig. 1:-Effect of different diets on AST and ALT activities. (SFO), sunflower oil group; (OO), olive oil group; (PSO), purslane seed oil group. Values represent the mean \pm SD for 10 rats/experimental group.

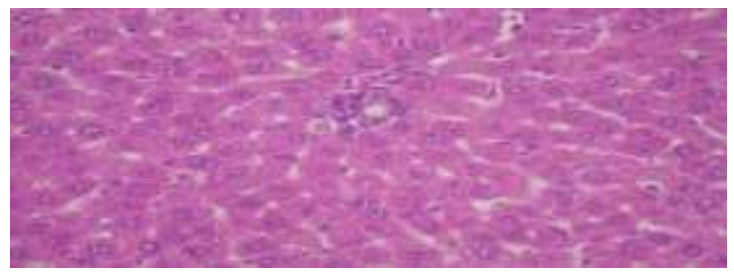

SFO

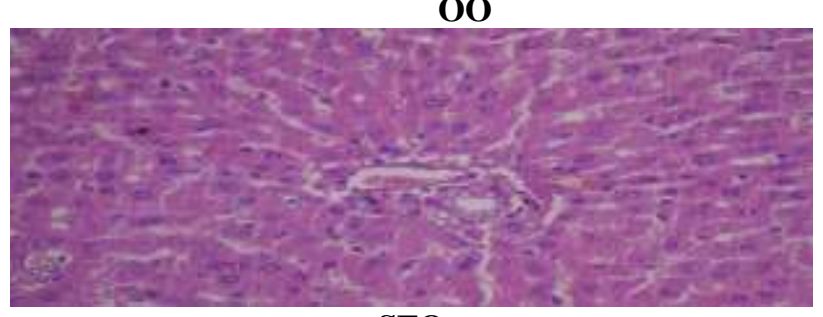

SFO

Fig. 2:-Hepatic histology of samples from all experimental groups. (SFO), sunflower oil group; (OO), olive oil group; (PSO), purslane seed oil group.

\section{Types of fatty acids in liver in different groups:-}

The percentages of the various fatty acids estimated in the liver samples for the three studied groups (SFO, OO and PSO) are shown in Table 3. There were no significant differences in the content of the three groups of total saturated fatty acids (TSFA). Oleic acid content was significantly higher in OO group compared with the other groups (SFO and PSO), while LA showed the highest value in SFO group compared with OO and PSO groups. On the other hand PSO group showed the highest ALA content compared with both OO and SFO groups. N-6 fatty acids were significantly higher in SFO group compared with other experimental groups, while PSO group was the highest in n3 fatty acids content compared with SFO and OO groups. The n-6/n-3 ratio was significantly decreased in PSO group compared with SFO and OO groups. Table (3) showed that SFO is the highest group in Arachidonic acid (AA) content, while PSO group showed the highest content of both eicosapentaenoic acid (EPA) and docosahexaenoic acid (DHA). 
Table 3:-Fatty acids compositions of the liver samples obtained from all experimental groups

\begin{tabular}{|l|l|l|l|}
\hline Fatty acid & SFO & OO & PSO \\
\hline Total saturated fatty acids (TSFA) & $36.3 \pm 1.7 \mathrm{a}$ & $37.3 \pm 1.2 \mathrm{a}$ & $38.9 \pm 1.7 \mathrm{a}$ \\
\hline Oleic acid (C18:1 n-9) & $15.03 \pm 0.4 \mathrm{~b}$ & $29.05 \pm 1.4 \mathrm{c}$ & $12.28 \pm 1.03 \mathrm{a}$ \\
\hline Linoleic acid (LA) (C18:2 n-6) & $24.04 \pm 1.16 \mathrm{c}$ & $8.4 \pm 0.7 \mathrm{a}$ & $13.3 \pm 1.06 \mathrm{~b}$ \\
\hline Arachidonic acid (AA) (C20:4 n-6) & $12.4 \pm 0.9 \mathrm{c}$ & $7.6 \pm 1.3 \mathrm{~b}$ & $2.4 \pm 0.3 \mathrm{a}$ \\
\hline Alpha-linolenic acid (ALA) (C18:3 n-3) & $0.35 \pm 0.04 \mathrm{a}$ & $0.34 \pm 0.02 \mathrm{a}$ & $3.4 \pm 0.6 \mathrm{~b}$ \\
\hline $\begin{array}{l}\text { Eicosapentaenoic acid (EPA) } \\
\text { (C20:5 n-3) }\end{array}$ & $0.21 \pm 0.02 \mathrm{~b}$ & $0.045 \pm 0.01 \mathrm{a}$ & $4.62 \pm 0.6 \mathrm{c}$ \\
\hline Docosahexaenoic acid (DHA) (C22:6 n-3) & $2.6 \pm 0.4 \mathrm{~b}$ & $0.067 \pm 0.02 \mathrm{a}$ & $3.14 \pm 0.8 \mathrm{c}$ \\
\hline n-6 fatty acids & $36.46 \pm 2.1 \mathrm{~b}$ & $16.07 \pm 0.99 \mathrm{a}$ & $15.8 \pm 1.3 \mathrm{a}$ \\
\hline n-3 fatty acids & $3.19 \pm 0.4 \mathrm{~b}$ & $0.45 \pm 0.02 \mathrm{a}$ & $11.16 \pm 0.8 \mathrm{c}$ \\
\hline n-6/n-3 ratio & $11.54 \pm 1.1 \mathrm{~b}$ & $35.44 \pm 1.3 \mathrm{c}$ & $1.41 \pm 0.1 \mathrm{a}$ \\
\hline
\end{tabular}

Values represent mean \pm SD for three samples. Total saturated fatty acids (TSFA) include (C:12, C:14, C:16, C:18, $\mathrm{C}: 20$ fatty acids).

\section{Discussion:-}

The data presented shows that the use of the three different oils in the preparation of experimental diets did not have any undesirable effect, as the animals maintained normal feed intake and growth rates throughout the experiment period (Table 2). The results showed no significant changes in liver status (liver weight - AST and ALT activities hepatic histology) in all studied groups.

The results obtained from the analysis of oils used in the preparation of different diets showed that the purslane seed oil is characterized by its high content of ALA and also characterized by a low n-6/n-3 ratio (Table 1), which harmonize to the results of previous studies (Liu et al., 2014; Osman and Hussein, 2015).

The content of fatty acids in the liver of the experimental rats in the different groups (Table 3 ) can be linked to the content of fatty acids in their diets (Table 1). This is confirmed by the significant increased in n-3 fatty acids (ALA, EPA and DHA) in the group fed on purslane seed oil (PSO) compared to the other two groups (SFO and OO). The high content of EPA and DHA in PSO can be explained by the high bioconversion rates of ALA to both EPA and DHA. The increase in EPA and DHA (n-3 LCPUFA) levels in PSO group was associated with a reduction AA (n-6 LCPUFA) level. Our results are in harmonic with other studies, which confirmed the relationship between ALA content in diet and accumulation of EPA and DHA (Araya et al., 2004; Cho et al., 1999; Wang et al., 2005). Our results also correlated with other studies suggesting that diets high in their ALA (n-3 precursor) content due to low levels of arachidonic acid (n-6 product) in plasma and tissues (Alsted and Hoy, 1992; Rambjor et al., 1996).

Results in Table (3) shown an inverse relationship between EPA + DHA content and AA content, which may be explained by well-known competition between LA (C18:2 n-6) and ALA (C18:3 n-3) at desaturation and elongation enzymes especially $\Delta-6$ desaturase (Emken et al., 1994). ALA (n-3) is elongated and desaturated to 24:6 (n-3) by the following steps, 18:3 desaturated to 18:4 followed by 18:4 elongated to 20:4 which desaturated to 20:5 (EPA), then EPA 20:5 elongated to 22:5 and elongated to 24:5 which desaturated to 24:6 after which 24:6 (n-3) is shortened to 22:6 (DHA) by one step of $\beta$-oxidation in peroxisomes (Sprecher, 2000; Wang et al., 2005).

Since the competition between ALA (n-3) and LA (n-6) to synthesize n-3 and n-6 long chain polyunsaturated fatty acids (EPA, DHA and AA), therefore, the consumption of oils containing a low $n-6 / n-3$ ratios (like purslane seed oil) is an important factor in the increase of n-3 LCPUFA (EPA and DHA).

Currently, many clinical studies have shown great health benefits of omega-3 fatty acids in resisting and reducing the impact of many diseases (Fetterman and Zdanowicz, 2009). However, low omega-3 diets are still observed in a lot of countries over the world, some of which may be replaced by dietary supplements from marine sources to compensate for omega-3 deficiencies (Abete et al., 2009). Nevertheless, the use of marine dietary supplements still faces many challenges, such as high prices, causing digestive disorders and the inability of vegetarians to eat them, as well as their contamination with toxic compounds, especially mercury (Bell et al., 2005; Sprague et al., 2010). In this context, shows the need of alternative sources of vegetable oils with a high content of ALA and a good ability to increase the biosynthesis of EPA and DHA. Purslane seed oils may be a good, available and safe source of ALA in 
Egypt, to provide great benefits of EPA and DHA in for many diseases (diabetes mellitus, cardiovascular diseases, cancer and obesity) (Mandal et al., 2010; Oliver et al., 2010; Roth and Harris, 2010).

In order to maximize the benefit of the results of this study, work should be completed on the preparation of meals containing these oils to support meals for humans, as well as, studying the extent to which people accept the taste of this oil.

\section{Conclusion:-}

Results from current study can confirm that the consumption of purslane seed oil didn't cause any damage to the liver cells morphologically and functionally in rats. Furthermore, this oil is characterized by its high ALA content, low n-6/n-3 ratio and increases hepatic levels of omega 3 family (ALA, EPA and DHA). These findings open the door to further study on the possibility of using purslane seed oil in the preparation of alternatives to food in daily meals to obtain the health nutritional recommendations of omega-3 fatty acids. Further work should be focused on the study of different metabolic pathways for ALA in human body.

\section{Acknowledgments:-}

This work was done with the full support of the Department of Biochemistry, Faculty of Agriculture, Menoufia University, Egypt

\section{References:-}

1. Abdalla, H.M. (2010): Purslane extract effects on obesity-induced diabetic rats fed a high-fat diet. Malays. J. Nutr., 16: 419-429.

2. Abdalla, H.M. and Mohamed, S.A.G. (2010): In vivo hepato-protective properties of purslane extracts on paracetamol-induced liver damage. Malays. J. Nutr., 16: 161-170.

3. Abete, P., Testa, G., Galizia, G., Della-Morte, D., Cacciatore, F. and Rengo, F. (2009): PUFA for human health: diet or supplementation? Curr. Pharm. Des., 15: 4186-4190.

4. Alsted, A. and Hoy, C. (1992): Fatty acid profiles of brain phospholipid subclasses of rats fed n-3 polyunsaturated fatty acids of marine or vegetable origin, a two generation study. Biochim. Biophys. Acta, 1125: 237-244.

5. Araya, J., Rodrigo, R., Videla, L.A., Thielemann, L., Orellana, M., Pettinelli, P. and Poniachik, J. (2004): Increase in longchain polyunsaturated fatty acid $\mathrm{n} 6 / \mathrm{n} 3$ ratio in relation to hepatic steatosis in patients with nonalcoholic fatty liver disease. Clin. Sci., 106: 635-643.

6. Araya, J., Rodrigo, R., Pettinelli, P., Araya, A.V., Poniachik, J. and Videla, L.A. (2010): Decreased liver fatty acid D-6 and D-5 desaturase activity in obese patients. Obesity, 18: 1460-1463.

7. Bancroft, J.D., Stevens, A. and Turner, D.R. (1996): Theory and practice of histological techniques. $4^{\text {th }}$ ed Churchill Livingstone; Edinburgh, London, Melbourne.

8. Bell, J.G., McGhee, F., James, R. and Dick Douglas, R.T. (2005): Dioxin and dioxin-like polychlorinated biphenyls (PCBs) in Scottish farmed salmon (Salmo salar): effects of replacement of dietary marine fish oil with vegetable oils. Aquacult., 243: 305-314.

9. Bligh, E.G. and Dyer, W.J. (1959): A rapid method of total lipid extraction and purification. Can. J. Biochem. Physiol., 37: 911-917.

10. Brenner, R.R. (2003): Hormonal modulation of D6 and D5 desaturases: case of diabetes. Prostag. Leukotr. Ess., 68: 151-162.

11. Cho, H.P., Nakamura, M. and Clarke, S.D. (1999): Cloning, expression, and fatty acid regulation of the human delta-5 desaturase. J. Biol. Chem., 274: 37335-9.

12. Cunnane, S.C. (2003): Problems with essential fatty acids: time for a new paradigm? Prog. Lipid Res., 42: 544568.

13. Dinh, T.K.L., Bourre, J.M., and Durand, G. (1993): Effect of Age and $\alpha$-Linolenic Acid Deficiency on $\Delta 6$ Desaturase Activity and Liver Lipids in Rats, Lipids, 28: 517-523.

14. Ebrahimzadeh, M.A., Nabavi, S.F. and Nabavi, S.M. (2009): Essential oil composition and antioxidant activity of Pterocarya fraxinifolia. Pak. J. Biol. Sci., 12: 957-963.

15. Emken, E.A., Adlof, R.O. and Gulley, R.M. (1994): Dietary linoleic acid influences desaturation and elongation of deuterium labelled linoleic and linolenic acids in young adult males. Biochim. Biophys. Acta, 1213: 277288.

16. Fetterman, J.W. and Zdanowicz, M.M. (2009): Therapeutic potential of n-3 polyunsaturated fatty acids in disease. Am. J. Health Syst. Pharm., 66: 1169-1179. 
17. Firestone, D. (1997): In Official Methods of Analysis of AOAC International (Cunniff, P., Ed.), pp. 963-964, Assoc. Official Anal. Chem., Gaithersburg, MD.

18. Harris, W.S. (2009): The omega-3 index: from biomarker to risk marker to risk factor. Curr. Atheroscler. Rep., 11: 411-417.

19. Holman, R.T. (1998): The slow discovery of the importance of omega 3 essential fatty acids in human health. J. Nutr., 128: 427S-433S.

20. Kamal-Eldin, A. and Andersson, R. (1997): A multivariate study of the correlation between tocopherol content and fatty acid composition in vegetable oils. J. Am. Oil Chem. Soc., 74: 375-380.

21. Kanai, S., Uto, K., Honda, K., Hagiwara, N. and Oda, H. (2011): Eicosapentaenoic acid reduce warfarininduced arterial calcification in rats. Atherosclerosis, 215: 43-51.

22. Lands, W.E., Libelt, B., Morris, A., Kramer, N.C., Prewitt, T.E., Bowen, P., Schmeisser, D., Davidson, M.H. and Burns, J.H. (1992): Maintenance of Lower Proportions of (n-6) Eicosanoid Precursors in Phospholipids of Human Plasma in Response to Added Dietary (n-3) Fatty Acids, Biochim. Biophys. Acta, 1180: 147-162.

23. Li, D. and Hu, X. (2009): Fish and its multiple human health effects in times of threat to sustainability and affordability: are there alternatives? Asia Pac. J. Clin. Nutr., 18: 553-563.

24. Liang, X., Tian, J., Li, L., Gao, J. and Zhang, Q. (2014): Rapid determination of eight bioactive alkaloids in Portulaca oleracea $L$. by the optimal microwave extraction combined with positive-negative conversion multiple reaction monitor (+/-MRM) technology. Talanta, 120: 167-172.

25. Liu, L., Howe, P., Zhou, Y.F., Xu, Z.Q. and Hocart, C. (2000): Fatty acids and betacarotene in australian purslane (Portulaca oleracea) varieties. J. Chromatogr. A, 893: 207-213.

26. Liu, L., Xie, C., Yue, L., Jing, S. and Cai Y. (2014): Preparation of Portulaca oleracea L. seed oil by ultrasound-assisted enzyme hydrolysis combined with Soxhlet extraction method and the analysis of its fatty acids. Food Ferment. Ind., 40: 218-222.

27. Mandal, C.C., Ghosh-Choudhury, T., Yoneda, T., Choudhury, G.G. and Ghosh-Choudhury, N. (2010): Fish oil prevents breast cancer cell metastasis to bone. Biochem. Biophys. Res. Commun., 402: 602-607.

28. Molendi-Coste, O., Legry, V. and Leclercq, I.A. (2011): Why and How Meet n-3 PUFA Dietary Recommendations? Gastroenterol. Res. Pract., Article ID 364040.

29. Nakamura, M.T. and Nara, T.Y. (2004): Structure, function, and dietary regulation of D6, D5, and D9 desaturases. Annu. Rev. Nutr., 24: 345-376.

30. Oliver, E., McGillicuddy, F., Phillips, C., Toomey, S. and Roche, H.M. (2010): The role of inflammation and macrophage accumulation in the development of obesity-induced type 2 diabetes mellitus and the possible therapeutic effects of long-chain n-3 PUFA. Proc. Nutr. Soc., 69: 232-243.

31. Orellana, M., Varela, N., Guajardo, V., Araya, J. and Rodrigo, R. (2002): Modulation of rat liver cytochrome P450 activity by prolonged red wine consumption. Comp. Biochem. Physiol. C. Toxicol. Pharmacol., 131: 161166.

32. Osman, S.M. and Hussein, M.A. (2015): Purslane seeds fixed oil as a functional food in treatment of obesity induced by high fat diet in obese diabetic mice. J. Nutr. Food Sci., 5: 332. doi:10.4172/2155-9600.1000332.

33. Picq, M., Chen, P., Perez, M., Michaud, M., Vericel, E., Guichardant, M. and Lagarde, M. (2010): DHA metabolism: targeting the brain and lipoxygenation. Mol. Neurobiol., 42: 48-51.

34. Rambjor, G.S., Walen, A.I., Windsor, S.L. and Harris, W.S. (1996): Eicosapentaenoic acid is primarily responsible for hypotriglyceridemic effect of fish oil in humans. Lipids, 31: S45-S49.

35. Roth, E.M. and Harris, W.S. (2010): Fish oil for primary and secondary prevention of coronary heart disease. Curr. Atheroscler. Rep., 12: 66-72.

36. Simopoulos, A.P. (2008): The importance of the omega-6/ omega-3 fatty acid ratio in cardiovascular disease and other chronic diseases. Exp. Biol. Med., 233: 674-688.

37. Sprague, M., Eldar, A., Bendiksen James, R.D, Fiona, S., Jarunan, P., Marc, H.G., Berntssen Douglas, R.T. and John, G.B. (2010): Effects of decontaminated fish oil or a fish and vegetable oil blend on persistent organic pollutant and fatty acid compositions in diet and flesh of Atlantic salmon (Salmo salar). Brit. J.Nutrit., 103: 1442-1451.

38. Sprecher, H. (2000): Metabolism of highly unsaturated n-3 and n-6 fatty acids. Biochim. Biophys. Acta, 1486: 219-231.

39. Young, D.S. (1990): Effects of drugs on clinical laboratory tests. $3^{\text {rd }}$ ed. AACC press; Washington DC (USA), 6 $-12 \mathrm{p}$.

40. Wang, Y., Botolin, D., Christian, B., Busik, J., Xu, J. and Jump, D.B. (2005): Tissue-specific, nutritional, and developmental regulation of rat fatty acid elongases. J. Lipid Res., 46: 706-715. 